\title{
POLIARQUÍA Y DEMOCRACIA
}

\author{
Roberto García Jurado*
}

De las dos palabras que dan título a este escrito, la segunda de ellas ha sido tan pronunciada y escuchada por personas asaz distintas y con finalidades igualmente diversas, que no es posible suponer que todas ellas han concebido una idea medianamente homogénea de su significado. Lo más probable es que éste ha sido muy distinto, de tal suerte que en la actualidad su sentido resulta totalmente relativo, y si en el pasado la pronunciación de esta palabra sirvió de divisa o lema a una fuerza política específica, en el mundo contemporáneo raramente se encontrará un partido político, un candidato a un cargo público o un gobierno que no se autonombren democráticos y rindan pleitesía a la democracia, tanto como instrumento como objetivo de su actividad.

Sucede todo lo contrario con la primera palabra del título. No es probable que una persona común conozca la palabra poliarquía y todavía es menos probable que sepa cuál es su significado. Incluso dentro del ámbito de los politólogos, sociólogos y economistas este término no es familiar, y aunque puede ser interpretado a través de su etimología, contiene un amplio sustento teórico muy poco conocido.

A pesar de que la popularidad y la extensión del uso de estos dos conceptos son tan contrastantes, se refieren a cosas muy similares, pues ambos aluden a los sistemas políticos actuales de las sociedades occidentales, y se diferencian sólo por la connotación particular que se

* Departamento de Política y Cultura, UAM-Xochimilco. 
les da en determinados contextos teóricos. Así, el interés central de este escrito es explicar y examinar el concepto de poliarquía que propone Robert Dahl, uno de los exponentes más sobresalientes de la teoría política norteamericana contemporánea.

En 1971 Robert Dahl publicó un libro con el nombre de La poliarquía. En él pretendió exponer el significado de este concepto, cuya utilidad primordial era que podía ser usado para describir los sistemas políticos de las llamadas democracias occidentales. No obstante, la exposición conceptual que hace Dahl en este trabajo es bastante escueta y vaga, pues no realiza, como podría esperarse, una amplia exposición del término, el cual no sólo intitula su libro, sino que además es central y fundamental en su pensamiento político. Así, para una interpretación aceptable de este concepto deben consultarse algunas de sus obras previas, entre las que desatacan Politics, economics and welfare que publicó en 1951 en coautoría con Charles Lindblom, Un prefacio a la teoría democrática de 1956 y Who governs? que apareció en 1961. Pero ni siquiera esto basta, pues desde que comenzó a usar el término hasta sus obras más recientes, Dahl lo ha estado enriqueciendo y reelaborando, por lo que es necesario aludir a varios más

40 de sus trabajos para comprender más amplia y extensamente la teoría e hipótesis que lo sustentan. Aunque la producción teórica de Dahl no se ha detenido en las últimas décadas, en sus escritos más recientes sigue respetado en términos generales el contenido original que diera a este concepto.

El sustento teórico y las implicaciones de la poliarquía son de una gran densidad, sin embargo, para ordenar su análisis, se pueden distinguir tres dimensiones o formas de comprenderla: 1) La poliarquía como aproximación a la democracia; 2) La poliarquía como control del liderazgo político; y 3) La poliarquía como pluralismo corporativo. Estas tres dimensiones se relacionan de múltiples formas y, de hecho, son complementarias; no obstante, su distinción y examen por separado pueden ser de gran utilidad para un análisis y comprensión más integrales. 
POLIARQUÍA Y DEMOCRACIA

\section{La poliarquía como aproximación a la democracia}

La manera más simple, directa y breve en que Robert Dahl define la poliarquía es la de que éste es el término que mejor describe a las sociedades democráticas realmente existentes. Esto significa que es necesario reconocer que la democracia es un orden utópico e ideal al que no puede aspirar la sociedad, pues su realización no está al alcance de la humanidad. ${ }^{1}$

Sin embargo, Dahl señala que es necesario aceptar que hay algunas sociedades que se encuentran más cerca de la democracia que otras, es decir, que existen algunas sociedades donde las desigualdades políticas son enormes, inmensas a veces, y otras en las que son menores. Así, las primeras están muy lejos de un orden político democrático, son sociedades monolíticas y donde seguramente impera la autocracia o alguna otra forma de gobierno totalitario, en tanto que las sociedades del segundo tipo están más cerca de la democracia y por lo tanto, para no caer en el exceso e imprecisión de llamarlas democráticas, puede usarse el término de sociedades poliárquicas.

${ }^{1}$ Dahl señala que existen una serie de características que deben cumplirse para la existencia de un orden plenamente democrático: 1) Que cada miembro exprese su preferencia, o sea, que vote; 2) Que influya por igual cada preferencia, cada voto; 3) Que triunfe la opción con mayor número de votos; 4) Que los individuos puedan insertar y elegir la opción preferida; 5) Que todos los individuos posean la misma información sobre todas y cada una de las alternativas propuestas; 6) Que las alternativas con mayor votación desplacen a las otras; 7) Que se ejecuten las órdenes de los representantes designados o se lleven a cabo las acciones elegidas; y 8) Que todas las elecciones que se realicen cumplan con estas siete condiciones o que se subordinen a ellas. Dahl apunta que algunas de estas condiciones son posibles, pero otras son poco menos que inalcanzables. Es decir, un orden social democrático pleno, como se concibe mediante estas condiciones, es irrealizable. Cfr. Un prefacio a la teoría democrática, 1987, México, Guernika. 
Planteado de esta manera, se deduce que la democracia es una cuestión de grado, de aproximación, es decir, una sociedad se aproxima o aleja de la democracia, pero nunca llega a la plenitud. ${ }^{2}$

Dahl reconoce que muchas sociedades modernas han llegado a la poliarquía mediante una revolución, en tanto que otras lo han hecho a través de medios pacíficos. Sin embargo, confía en que una vez que la sociedad ha llegado a la poliarquía las revoluciones y cambios bruscos dejan de ser posibles, la poliarquía es el fin de la historia política de la sociedad, después de ella no hay ninguna forma de gobierno que pueda sustituirla ni el deseo de la sociedad para hacerlo. ${ }^{3}$

El marco institucional de una poliarquía permite que todos los cambios necesarios en la sociedad se realicen gradualmente, a través de lo que Dahl llama el incrementalismo, el cual ocupa un lugar destacado en el aparato conceptual de los estudiosos de las políticas públicas y es heredero directo del principio de optimización paretiano. No obstante, la manera en que lo presenta Dahl es bastante elemental, al grado de asemejarlo con una política gubernamental basada en la técnica de prueba y error. 4

Debido a esta concepción de la historia y a las tesis fundamentales 42 de su teoría política, bien podría inscribirse a Dahl en la corriente teórica que en los años cincuenta se difundió con gran intensidad en el

2 "Debido a que las organizaciones humanas rara vez y quizá nunca alcanzan el límite establecido por estas ocho condiciones, es necesario interpretar cada una de ellas como un extremo de un continuo o de una escala a lo largo de la cual se puede medir cualquier organización. Desafortunadamente, en la actualidad no existe ninguna forma conocida de asignar valores, si pudieran medirse las ocho escalas, sería posible, y tal vez útil, establecer clases arbitrarias pero no carentes de sentido, de las cuales el plano superior podría llamarse poliarquías." Ibid. p. 98.

${ }^{3}$ La historia da muchos ejemplos de rupturas del orden democrático dentro del mismo mundo occidental. Una notable exposición y examen de los peligros que amenazan a la democracia es el libro de Juan Linz, La quiebra de las democracias, 1990, México, Alianza-Conaculta.

${ }^{4}$ Cfr. Politics, economics and welfare, 1963, Nueva York, Harper and Row. 


\section{POLIARQUÍA Y DEMOCRACIA}

mundo occidental, particularmente en Estados Unidos, y que se conoció con el nombre del fin de las ideologías. Esta teoría postulaba que en el mundo contemporáneo había dejado de tener sentido plantearse la alternativa de elegir excluyentemente entre dos tipos de organización social, es decir, que ya no era pertinente la disyuntiva de elegir entre economía de mercado y planificación centralizada, entre socialismo y capitalismo. Evidentemente, estas consideraciones se nutrían de la observación de las nuevas políticas sociales y económicas de los gobiernos occidentales, las cuales, tras los desastres provocados por la guerra, dieron un aspecto notablemente distinto a las sociedades capitalistas, haciéndolas aparecer mucho más sensibles a las carencias de los sectores de la población con menores recursos y apartándolas de la imagen del capitalismo salvaje e inhumano que hasta entonces había sido el rostro de este sistema económico. ${ }^{5}$

Desde esta perspectiva, no sólo había dejado de tener sentido plantearse la alternativa entre socialismo y capitalismo en términos teóricos, sino que además el mundo real era una prueba fehaciente de ello. El efecto de las políticas de seguridad social, el aumento general del ingreso, los impuestos progresivos, los impuestos sobre las herencias, etc., provocaban que en el mundo occidental la igualdad y la justicia por la que luchaba el socialismo pudiera darse dentro de una economía capitalista, la cual era llamada así sólo por convención, pues en ella se habían registrado modificaciones relevantes que transformaban no sólo su forma sino también su esencia.

En este sentido, dado que no había ya una diferencia dicotómica entre capitalismo y socialismo, puesto que el primero había tomado del segundo algunas prácticas e instituciones que lo mejoraban, no había ya tampoco necesidad de elegir entre uno y otro; era conveniente quedarse con el capitalismo. Así, afianzada una economía capitalista,

${ }^{5}$ Una elemental documentación al respecto debe incluir el texto de Daniel Bell, El fin de las ideologías, 1992, Madrid, MTSS; el de Seymur Martin Lipset, El hombre politico, 1993, México, REI; y el de Francis Fukuyama, El fin de la historia y el último hombre, 1992, México, Planeta. 
ROBERTO GARCIAA JURADO

lo que se requería para instaurar la justicia y la equidad era simplemente elegir entre técnicas sociales. Sólo era necesario recurrir a la mejor fórmula de agrupar las fuerzas sociales y la forma óptima de utilizar sus recursos. De acuerdo con su análisis, Dahl identificaba cuatro técnicas sociales fundamentales: 1) El sistema de precios, que creaba espacios donde competían oferentes y demandantes de determinados productos 2) La jerarquía, que estructuraba una línea de mando vertical en determinadas instituciones cuyo grado de especialización o tipo de operación así lo requería, 3) La poliarquía, que era el sistema mediante el cual en ciertas organizaciones los no-líderes controlaban a los líderes y 4) La concertación, que era un mecanismo para llegar a acuerdos entre distintos grupos de líderes.

De esta forma, al optar por alguna de estas cuatro técnicas sociales, se podía elegir la forma más racional de dirigir la acción social y solucionar los problemas sociales más acuciantes.

Las transformaciones económicas y políticas de fin de siglo parecen confirmar las tesis que se difundieron en los años cincuenta, pues ahora ya ni siquiera existe el bloque socialista. Sin embargo, las sociedades occidentales están todavía lejos de solucionar sus problemas eco-

44 nómicos, políticos y sociales. Los problemas de la democracia siguen tan candentes como hace medio siglo, y si prácticamente ha desaparecido su contrincante, el socialismo, ello no significa que paralelamente se hayan resuelto sus problemas. ${ }^{6}$

Así pues, ahora más que nunca, es pertinente preguntarse qué debe entenderse por democracia en el mundo contemporáneo, pues si puede aceptarse sin mayores objeciones que los regímenes despóticos, tiránicos o autocráticos no son deseables para el conjunto de la sociedad, no resulta del todo claro qué características debe llenar un orden político deseable y factible para la sociedad en su conjunto.

${ }^{6}$ Acerca del triunfo de la democracia y la economía capitalista de este fin de siglo puede consultarse el lúcido ensayo de Giovanni Sartori, La democracia después del comunismo, 1994, Madrid, Alianza. 
Es necesario especificar el significado contemporáneo de la democracia porque $-\mathrm{y}$ no está por demás volver a esta vieja y persistente polémica- en la teoría política de la antigüedad clásica tenía una connotación esencialmente negativa. De acuerdo con Aristóteles, por ejemplo, era una forma de gobierno corrupta, donde una parte de la sociedad, los muchos, ejercía el gobierno de una forma despótica sobre el resto. ${ }^{7}$ Aun en plena época moderna, Kant se refería a la democracia como la versión corrompida de la república, pues en tanto dentro de ésta no había ninguna parte de la sociedad que deseara imponer su soberanía sobre el resto, en la democracia se presentaba esa aspiración por parte de un sector social, y aunque se tratara del más numeroso, ello no implicaba que no existiese la pretensión de imponer la voluntad de una parte sobre otra. ${ }^{8}$

Dahl señala que a pesar de que la democracia en el mundo antiguo griego implicaba una noción de igualdad política (isogornia, isonomia) ${ }^{9}$ un modelo de gobierno popular y el supuesto de la formulación colectiva de la ley, su realización y práctica eran bastante imperfectas, pues

${ }^{7}$ Sin embargo, Dahl no está de acuerdo con que en la antigua Grecia la democracia tuviera una connotación negativa. Argumenta que si esta idea ha llegado hasta nosotros es porque sólo se han conservado los testimonios de los críticos y enemigos de la democracia, como Aristóteles y Platón. Dahl no toma en cuenta que Aristóteles, por ejemplo, no era enemigo del gobierno popular, pues en su teoría de las formas de gobierno concibe que puede haber dos tipos: el gobierno constitucional; en el cual la mayor parte de los ciudadanos gobierna en beneficio de la sociedad en general; y la democracia; en la cual ese mismo sector social gobierna en provecho de sí mismo, dañando al resto de la sociedad. Cfr. Robert Dahl, La democracia y sus criticos, 1992, Barcelona, Paidós; Aristóteles, Política, 1990, Madrid, Alianza; y Norberto Bobbio, La teoría de las formas de gobierno en la historia del pensamiento político, 1992, México, FCE.

${ }^{8} \mathrm{C}$ fr. Immanuel Kant, La paz perpetua, 1990, México, Porrúa.

${ }^{9}$ Isogornia: igualdad de todos los ciudadanos en cuanto a su derecho de hablar en la asamblea de gobierno. Isonomia: igualdad de los ciudadanos ante la ley. 
ROBERTO GARCÍA JURADO

la exclusión de los esclavos de los derechos políticos en la ciudadesEstado griegas hacía bastante cuestionable el valor de la democracia para la sociedad en su conjunto. Además, la imposibilidad de que una asamblea de ciudadanos otorgara las mínimas posibilidades reales para que todos los ciudadanos presentes se expresaran sobre los asuntos públicos, hacía todavía más defectuoso el sistema democrático. ${ }^{10}$

Así, a pesar de las pretensiones políticas igualitarias de la democracia griega, su práctica y funcionamiento eran bastante imperfectos, característica que compartiría con los sistemas democráticos de los Estados modernos. Sin embargo, para Dahl, las diferencias entre las ciudades-Estado griegas y los modernos Estados-nación hacen inadecuado aplicar el concepto de democracia a ambas realidades: "La claridad podia haber sido mejor servida si el término 'democracia' nunca hubiera sido transportado a los ideales e instituciones asociadas con el gobierno popular directo de las ciudades-Estado hacia los ideales e instituciones asociadas con el gobierno representativo en el Estadonación. Los dos sistemas políticos son bastante distintos como para conjuntarlos o permanecer en una sola categoría." 11

De acuerdo con su argumentación, en las ciudades-Estado griegas 46 existía una relativa armonía de intereses, un alto grado de homogeneidad, y una reducida cantidad de ciudadanos, asimismo, se daba la práctica de la resolución colectiva y directa de los problemas de la polis, todo lo cual no se presenta en los Estados modernos, por lo que resulta inconveniente transportar la noción de la democracia de aquéllas a éstos.

No obstante estas diferencias, por las que Dahl prefirió no usar el concepto de democracia y se abocó a forjar un concepto alternativo (poliarquía), el pensamiento político moderno rescató, revaloró y ponderó positivamente el concepto de democracia.

${ }^{10}$ Cf. Robert Dahl, La democracia y sus críticos, op. cit., y Los dilemas. del pluralismo democrático, 1991, México, Alianza-Conaculta.

${ }^{11}$ Robert A. Dahl and Edward R. Tufte, Size and democracy, 1973, Stanford, U. P., p. 25. 
Durante el siglo XIX, y más propiamente en el presente, la democracia adquirió su sentido positivo y deseable. Cada vez con mayor extensión se le comenzó a identificar como la forma de gobierno en la cual los ciudadanos gozaban de una mayor igualdad política y luego, con la transformación del Estado liberal del siglo XIX al Estado social del siglo XX, se comenzó a adjuntar a la igualdad política una serie de derechos sociales que poco a poco se fueron convirtiendo en parte del régimen democrático. Con lo cual, la democracia que durante el siglo XIX significó sobre todo la lucha por la extensión del sufragio a la universalidad de los ciudadanos de un Estado, durante el presente siglo se convirtió en un régimen donde además de asegurar la igualdad política, se persigue eliminar las desigualdades económicas extremas y se asumen mayores y más extensos preceptos de justicia social.

Sin embargo, si bien la mayor parte de las corrientes políticas aceptan sin gran reticencia que un orden político deseable, un orden democrático, debe partir del principio indiscutible de la igualdad de los derechos políticos, en el momento de fijar el tipo y sentido de los derechos sociales y económicos que deben disfrutar los ciudadanos, es decir, de los aspectos de la vida social a los cuales debe extenderse la igualdad, entonces deja de haber consenso; es decir, mientras unos se inclinan por una igualdad social y económica mayor, otros aseguran que la igualdad política es suficiente, y que el resto de las atribuciones y usufructos del ciudadano deben ser producto de su esfuerzo individual. ${ }^{12}$

Planteado en estos términos, puede parecer maniquea y simplista la cuestión de la democracia, lo que no es asi en absoluto, pues si se ha

${ }^{12}$ Dahl y Lindblom analizan ampliamente este tema en Politics, economics and welfare. Allí plantean que en términos sociales los incentivos monetarios son tanto una recompensa como un recurso: el aumento de los ingresos de los sectores bajos puede producir tal aproximación que los incentivos pierdan su efectividad, pues la igualdad generalizada produce apatía. Además, los incentivos monetarios juegan un papel importante en la distribución del tiempo de trabajo y el ocio; una igualdad generalizada puede inclinar hacia el ocio de una manera inconveniente, sobre todo si se llegara a concebir el ingreso elevado como producto de un derecho y no de un esfuerzo. Cfr. Cap. 5. 
reducido a tan sólo dos corrientes teóricas polarizadas lo que en realidad es una cuestión mucho más compleja, esto se debe al propósito de mostrar la dificultad de establecer certeramente lo que significa el concepto de democracia en el mundo contemporáneo. En este caso en particular, la mención de estas dos tendencias fundamentales permite ilustrar mejor las implicaciones de la pregunta que anteriormente se formuló ¿Qué debe entenderse por democracia en el mundo contemporáneo?

De acuerdo a las condiciones que señala Robert Dahl (ver nota 1), la democracia es un mecanismo para que un determinado número de individuos tome decisiones colectivas obligatorias, es decir, la democracia es sobre todo una cuestión de igualdad de derechos participativos. Así, en buena medida, Dahl retoma a Schumpeter, para quien "la democracia es un método político, es decir, un cierto tipo de concierto institucional para llegar a decisiones políticas y por ello no puede constituir un fin en sí misma, independiente de las decisiones a que dé lugar en condiciones históricas dadas". ${ }^{13}$

$\mathrm{Al}$ entender la democracia sólo como un método para adoptar determinadas decisiones, Schumpeter no acepta que a este régimen se asocien nociones de igualdad y justicia social, pues lo determinante es el procedimiento, no el resultado. Dahl, con sus ocho condiciones, asume una posición similar. Sin embargo, mientras Schumpeter alude a la democracia como forma de gobierno de un Estado, Dahl se refiere a ella de una manera ambivalente: como forma de gobierno para un Estado y como procedimiento decisorio disponible para organizaciones sociales específicas, ya se trate de un sindicato, una empresa o una asociación profesional. Debido a esta ambivalencia, su teoría se presta a una serie de equívocos notables.

Si se acepta la concepción democrática que propone Dahl, entonces debe concluirse que la democracia no es necesariamente un orden utópico e inalcanzable, pues habrá ciertas organizaciones sociales pequeñas y con un alto grado de homogeneidad donde se satisfagan las ocho

13 Joseph Schumpeter, Capitalismo, socialismo y democracia, 1983, Barcelona, Orbis. 
condiciones requeridas. Sin embargo, si se trata de una organización social mayor, como un Estado, por ejemplo, entonces deberá aceptarse que esas ocho condiciones son ciertamente de muy difícil realización.

Ahora bien, ya que Dahl aplica el mismo criterio en ambos casos, cabe preguntarse si los asuntos que conciernen a uno y otro tipo de organización son de la misma naturaleza. Es decir, en un sentido más estricto, debería preguntarse si las propias organizaciones sociales consideradas (un sindicato, una asociación profesional o un Estado) son de la misma naturaleza.

La respuesta es evidente: ni la naturaleza ni los asuntos concernientes a cada uno de estos tipos de organización son equiparables. En los sindicatos, las asociaciones profesionales, las juntas vecinales, etc., los miembros entran normalmente de una manera voluntaria, transitoria y, además, estas organizaciones se vinculan con un espacio parcial de las actividades vitales de los individuos. En este tipo de organizaciones se toman y asumen decisiones relacionadas con aspectos de una gran especificidad, razón por la cual es más probable que se alcance la satisfacción de las ocho condiciones que Dahl identifica para aceptar la existencia de un orden democrático.

En cambio, si se trata de un Estado, las condiciones cambian radicalmente. En primer lugar, no se pertenece a un Estado de manera transitoria o voluntaria; no se elige convertirse en ciudadano de éste o aquel Estado, ya que normalmente se nace en uno de ellos y en ellos transcurre la mayor parte de la vida. Además, los ciudadanos de un Estado normalmente no toman decisiones sobre asuntos particulares, sino que eligen a quienes lo hagan en su representación.

Las diferencias entre estas organizaciones sociales no permite aplicar a ambas el mismo concepto de democracia. Ésta es, pues, una de las confusiones más persistentes en la teoría de Dahl: no diferencia a la democracia en tanto procedimiento decisorio de una determinada organización, de la democracia como forma de gobierno de un Estado. Si se trata de la democracia como un proceso de toma de decisiones, en ciertas organizaciones sociales es factible, pero si se trata de un Estado, entonces es algo de difícil realización. 
En términos sociales, como una forma de gobierno para un Estado, la democracia es mucho más que un mecanismo para la adopción de decisiones colectivas obligatorias. Es necesario reconocer que en el mundo contemporáneo la igualdad de los derechos políticos y el respeto irrestricto de los procesos democráticos para adoptar decisiones determinadas, o para elegir a los gobernantes de una sociedad, son componentes esenciales e imprescindibles de la democracia. Sin embargo, no es posible imaginar un orden social democrático en el que estén ausentes las mínimas consideraciones sobre equidad económica y justicia social.

Para ilustrar mejor la confusión que introduce Dahl, es conveniente destacar que él mismo acepta que el funcionamiento de la democracia requiere de ciertas condiciones sociales y económicas. Para mostrarlo bastan dos ejemplos, el primero de ellos contenido en esta larga cita:

Si bien el sufragio universal e igualitario es necesario para el proceso democrático, se sabe, sin embargo, desde hace mucho que es insuficiente, porque el voto sólo es un tipo de recurso político. Debido a que los recursos sociales están distribuidos desigualmente, y debido a que muchos tipos de recursos sociales pueden convertirse en recursos políticos, los recursos políticos distintos al voto están distribuidos desigualmente.

Un remedio más reciente es imponer mínimos y máximos a los recursos políticos. Al poner suelos a los recursos sociales disponibles para todos los ciudadanos-por ejemplo, la educación universal, libre y obligatoria y un ingreso básico proporcionado por la seguridad social y los pagos de bienestar social-se garantiza una dotación mínima de recursos políticos a todos los ciudadanos. Además se fijan los techos hasta el punto en el cual ciertos recursos sociales, sobre todo el dinero, pueden legalmente ser convertidos en recursos políticos, por ejemplo, mediante límites a las contribuciones de campaña. ${ }^{14}$

${ }^{14}$ Robert Dahl, Los dilemas del pluralismo..., op. cit., p. 165. 


\section{POLIARQUÍA Y DEMOCRACIA}

El segundo ejemplo consiste en las tareas pendientes que Dahl asigna a la poliarquía de Estados Unidos: 1) La eliminación de las desigualdades institucionalizadas por las tradición, como el racismo contra negros, hispanos y orientales, 2) La reducción de las desigualdades de riqueza e ingreso, y 3) La minimización de las desigualdades para el acceso a la educación y los diferenciales culturales que esto provoca. ${ }^{15}$ Es decir, si la democracia es simplemente un mecanismo de toma de decisiones, por qué se hace necesario que para aproximarse a ella se requiera reducir las desigualdades económicas, sociales y educativas? Esto significa que Dahl se ve obligado a reconocer que como régimen político la democracia requiere de algo más que las ocho condiciones que consideraba.

En este sentido, debe quedar claro que actualmente no puede pretenderse que la democracia implique una igualdad económica, social y política absoluta, situación que seguramente no es deseable para nadie, pues sus horrores han sido convincentemente esbozados en las antiutopías del siglo XX. Pero también es necesario destacar que sin determinados niveles mínimos de vida se hace inoperante la estructura procedimental de la democracia.

Para alcanzar esos niveles mínimos de vida, la extensión de la igualdad de derechos políticos al grueso de la sociedad ha sido muy importante. A través del ejercicio de los derechos políticos los estratos de menores recursos han logrado que la riqueza social se distribuya mejor y se modifique sustancialmente el esquema de redistribución fiscal. Sin embargo, no es posible aceptar, como lo pretende Dahl, que para que se produzca una distribución del ingreso igualitaria y una transformación de la redistribución fiscal, basta con que los electores así lo decidan.

La cuestión no es tan simple, pues de aceptar sin más esta premisa, se debe suponer que en un sistema poliárquico se da una redistribución fiscal acorde a las preferencias del electorado y, para cambiarla, basta con que el electorado manifieste su voluntad. La conclusión sería eviden-

${ }^{15}$ Cfr. Robert Dahl, Democracy in the United States: promise and performance. 
te: en la actualidad, las sociedades poliárquicas tienen la estructura de redistribución fiscal que desean los ciudadanos. ${ }^{16}$

Ahora bien, si es cierto que en una poliarquía se respetan las preferencias de la mayoría del electorado, ¿por qué no parece tan convincente que basta la voluntad de los ciudadanos para emprender la redistribución de la riqueza y una distribución distinta de los recursos públicos?

En primer lugar, debe recordarse que en los sistemas políticos contemporáneos los ciudadanos no toman decisiones sobre asuntos en particular. Sería pertinente preguntarse, por ejemplo, qué sucedería si los gobiernos de las poliarquías contemporáneas que Dahl reconoce como tales convocaran a un plebiscito sobre la distribución del ingreso y presentaran una serie amplia de propuestas alternativas. Todo esto es pura especulación, pero es muy posible que el resultado fuera una alternativa distinta a la que realmente existe en esos países.

Así pues, es necesario reconocer que aún en una poliarquía las acciones de gobierno no siempre coinciden con la voluntad del electorado. Probablemente la democracia sea la manera más adecuada para reducir la brecha que existe entre esos dos factores, pero no puede pasarse por alto que su confluencia absoluta es algo irrealizable y, todavía más notoriamente, que las democracias actuales difícilmente pueden atribuirse esa capacidad.

Finalmente, es conveniente insistir en que una de las principales fuentes de confusión es la no diferenciación entre la democracia como proceso de toma de decisiones y la democracia como régimen político. En este sentido, si nos referimos a la democracia como régimen político, es cierto que la poliarquía está mucho más cerca de los ideales democráticos que otros regímenes, pero no sólo porque el electorado puede ver automáticamente cumplidas y materializadas sus expectativas en

${ }^{16}$ En La poliarquía, publicada en 1971, Dahl enumera los países que a su juicio podrían ser considerados poliarquías o cuasipoliarquías, en los que se incluyen a casi todos los países de Europa occidental, algunos del continente americano y unos cuantos de Asia. 
las acciones de gobierno y en la reglamentación y organización de la estructura económica y social, sino porque a lo largo de un sinuoso y complejo proceso histórico se llegó al reconocimiento de una serie de derechos civiles y sociales, con lo cual puede construirse una sociedad menos oligárquica y con menores desequilibrios de ingreso.

\section{La poliarquía como control del liderazgo político}

Dahl lo menciona explícitamente: la poliarquía consiste esencialmente en que los no-líderes ejerzan un alto grado de control sobre los líderes. ${ }^{17}$ Para ampliar esta perspectiva, es conveniente observar cómo en varias de las obras de Dahl se señalan siete requisitos básicos que debe cumplir un sistema político para que pueda considerarse una poliarquía, los cuales despliegan la propia definición de la poliarquía como control del liderazgo:

1. El control sobre las decisiones gubernamentales en relación con la política debe estar otorgado constitucionalmente a los funcionarios elegidos.

2. Estos funcionarios son elegidos y desplazados pacíficamente en períodos preestablecidos, en lugares en que se celebran elecciones libres y en las que la coerción no existe o está francamente limitada.

3. Prácticamente todos los adultos tienen derecho al voto.

4. La mayoría de los adultos tiene derecho a postularse para los puestos públicos.

5. Los ciudadanos tienen la oportunidad de expresarse libremente en relación a la política, de criticar al gobierno y a la ideología predominante.

${ }^{17}$ Dahl lo dice de varias formas "...la teoría democrática se relaciona con los procesos por medio de los cuales los ciudadanos comunes ejercen un grado relativo de control sobre los dirigentes." Un prefacio a la..., op. cit., p. 11. 
6. Los ciudadanos tienen acceso a fuentes alternas de información.

7. Los ciudadanos tienen derecho a unirse y asociarse en organizaciones autónomas de todo tipo, incluido el político. ${ }^{18}$

Como podrá observarse, a partir de estos siete requisitos se deduce que la poliarquía es sobre todo una cuestión de control, cambio y renovación de gobernantes.

Es en este aspecto donde mejor se puede apreciar la aproximación de Dahl a la tradición liberal de la que se nutre. Para él, la cuestión más relevante de la política es el antiguo y recurrente problema de cómo los ciudadanos pueden evitar que sus gobernantes se conviertan en tiranos. ${ }^{19}$

De acuerdo con esta concepción, el hombre es por naturaleza un tirano, un tirano en potencia, es decir, ante ausencia de límites y controles externos sus apetitos lo llevan inconteniblemente a someter y dominar despóticamente a sus semejantes. De esta manera, considerando que el gobierno es necesario para mantener el orden social, pero que por el otro lado sus ocupantes amenazan constantemente a sus miembros mediante la extralimitación de sus funciones, la tarea más

54 importante de la política es establecer diques y contenedores sociales y constitucionales que controlen y limiten la actividad de los gobernantes. ${ }^{20}$

${ }^{18}$ Estos siete requisitos pueden encontrarse con variaciones mínimas en las siguientes obras: Reflexiones sobre la democracia contemporánea; Politics, economics and welfare; La poliarquía; y Modern political analysis.

${ }^{19}$ Politics, economics and welfare, p. 273 . Un poco más adelante, citando libremente a Jouvenel, dice que toda la historia de la humanidad se concentra en el creciente control sobre el gobierno, p. 273-4.

${ }^{20}$ Macpherson y Hell han estudiado las distintas acepciones que se le han otorgado a la democracia en los dos últimos siglos, y a este tipo de democracia concebida fundamentalmente por Bentham y John Stuart Mill, es decir, a la que considera que lo más importante es proteger a la ciudadanía de los excesos del gobierno, le han dado el nombre de democracia de protección. Cfr. C.B. Macpherson, La democracia liberal y su época, 1991, Madrid, Alianza y David Hell, Modelos de democracia, 1992, México, Alianza. 
Dahl entiende a la sociedad como una agrupación de seres humanos caracterizada esencialmente por el conflicto, y que la virtud republicana, consistente sobre todo en anteponer el interés público al particular, es sólo un mito histórico y político, pues en realidad nunca ha existido. Por tal razón, ausente todo rastro de virtud republicana de las motivaciones políticas primarias, no hay mas remedio que contener los intereses particulares y las aspiraciones de dominio innatas en todo ser humano.

En congruencia con la más recalcitrante tradición liberal, Dahl considera que las bondades de un sistema político radican en su capacidad para proteger a los ciudadanos contra los excesos del gobierno. De esta manera, no puede esperarse ninguna capacidad creadora o benefactora por parte del gobierno: el mejor gobierno es el que gobierna menos.

No obstante, una innovación llamativa de la teoría de Dahl es que no sólo los líderes políticos, es decir los gobernantes, requieren ser sometidos al control de los no-líderes, sino que también los "líderes económicos" deben ser sometidos a este control. En un sistema político poliárquico, donde existan las siete condiciones mencionadas anteriormente, los no-líderes pueden controlar a los líderes mediante el voto. Del mismo modo, en el espacio del mercado, los no-líderes pueden controlar a los líderes mediante el consumo y el sistema de precios. Esto significa que los dos espacios de acción y convivencia más importantes de la sociedad, la política y la economía, pueden ser definidos y normados mediante el control de los líderes por los no-líderes, los cuales serán efectivos siempre y cuando exista en el primer caso un sistema electoral acorde a las siete características mencionadas de la poliarquía y, en el segundo, un sistema de precios eficiente, capaz de "limpiar" el mercado y operar sin distorsiones.

En este aspecto, siguiendo de nueva cuenta a Schumpeter, Dahl plantea que así como en el campo de la economía la acción social racional está mejor servida si se cuenta con un sistema de mercado, el cual tendrá la cualidad de emplear y distribuir de una manera más eficiente los recursos de la sociedad, del mismo modo, en el campo de la 
política, la acción social racional tendrá su mejor vehículo en un sistema electoral abierto, el cual podrá controlar más adecuadamente a los gobernantes y proteger convenientemente a la sociedad en contra de sus excesos. ${ }^{21}$

Dahl no toma en cuenta que así como el mercado tiene una serie de imperfecciones que no siempre ni en todas las circunstancias lo convierten en el mejor asignador de recursos, del mismo modo, un sistema electoral que cumpla con las especificaciones mencionadas no estará libre de operar sin distorsiones ni garantizará por sí solo la expresión de las preferencias políticas de los ciudadanos.

De acuerdo a la argumentación de Dahl, un sistema poliárquico podrá expresar las preferencias e intereses de los ciudadanos en tanto tenga la capacidad de incorporar de manera fluida y automática estas preferencias. Es decir, desde el momento en que no hay restricciones a la formación de organizaciones políticas, al cuestionamiento de las decisiones gubernamentales, a la posibilidad de ocupar cargos de elección popular y a la facultad de votar, entonces los contendientes deberán responder ineludiblemente a las preferencias ciudadanas, pues de no hacerlo corren el riesgo de perder el favor del electorado y consecuentemente ser vencidos en las elecciones ante sus contrincantes, los cuales, seguramente sí habrán sido capaces de representar las demandas de la mayoría ciudadana. Por lo que, aún si los ciudadanos se encuentran en una posición en la cual ningún partido político contendiente o ningún candidato a un puesto de elección popular se comprometa a defender su causa, espontáneamente surgirá de entre la propia ciu-

${ }^{21}$ Schumpeter insistía en que no hay instrumento más democrático que el mercado, ni tampoco ninguno que dé las oportunidades más amplias al talento, pues los consumidores se caracterizan por maximizar sus recursos a través de la elección de las mejores ofertas, lo que automáticamente desecha a los oferentes que no sean eficientes y no cumplan con sus exigencias. De este modo, Schumpeter definía a la democracia esencialmente como un mercado politico en el que se ofertan y demandan líderes. Cfr. Capitalismo, socialismo $y$ democracia, op. cit. 
dadanía un líder que sí asuma ese mandato y atraiga la preferencia ciudadana. $^{22}$

En esta perspectiva, los sistemas poliárquicos disfrutan de tal porosidad y ductibilidad que pueden absorber fácilmente las demandas ciudadanas e impedir que el malestar social se exprese por un medio distinto al de las preferencias electorales. Como cualquier observador atento de la realidad podría atestiguar, ése no es el comportamiento real y normal de los sistemas políticos, pues éstos tienen una estructura institucional, un marco reglamentario y un entramado de prácticas y costumbres que establecen una línea divisoria entre el sistema político y la sociedad; es decir, si Dahl considera que un sistema poliárquico es capaz de responder ágilmente a las preferencias ciudadanas, habría simplemente que señalar la persistencia y durabilidad de, por ejemplo, los sistemas de partidos, las legislaciones electorales y la red de medios de expresión de la opinión pública, para así mostrar que incluso un sistema poliárquico no es ni lo poroso, dúctil o maleable que describe.

La dinámica social está compuesta por algo más que decisiones, como parece pretender Dahl. Las sociedades son construcciones históricas, formadas por instituciones, estructuras y accidentes que contribuyen a establecer un tejido social en el cual se inserta el individuo. Además, dentro de la sociedad existen distintos agentes económicos, políticos y culturales sobre los cuales el electorado, como instancia de decisión política, tiene distintos niveles de alcance: en algunos casos las decisiones son de efecto inmediato, pero en otros más retardadas e indirectas.

Estas suposiciones de Dahl se fundan en gran medida en la idea que tiene de la sociedad y su dinámica. Para él la sociedad está compuesta de líderes y no-líderes en todos y cada uno de los espacios de acción

${ }^{22}$ Giovanni Sartori es uno de los pocos teóricos políticos contemporáneos que ha retomado y usado el concepto de poliarquía. Su interpretación es muy interesante y su concepto de poliarquía de mérito enriquece y realza la versión original. Cfr. Teoría de la democracia, 1991, México, Alianza. 
humana: politica, economía y cultura. ${ }^{23}$ Asimismo, la sociedad se mueve en el sentido que le imprimen estos líderes, el control que ejercen sobre ellos los no-líderes y la interacción de los distintos grupos de líderes entre sí. Al separar así a la sociedad, Dahl evoca el anhelo liberal de imaginar que dejada a su libre interacción la sociedad da la oportunidad de destacar dentro de cada una de sus actividades a los hombres que se apliquen y esfuercen en ello, es decir: el camino del éxito está abierto y la sociedad es capaz de reconocerlo y seguirlo.

Sin embargo, las sociedades contemporáneas no parecen responder a esta descripción, pues tanto las estructuras económicas como las políticas tienen fuertes resistencias e inercias que difícilmente podrían funcionar a partir de la simple separación entre los que se convierten en líderes y los que no alcanzan esa posición.

Esta forma de concebir a la sociedad tiene origen en buena medida en la interpretación de la historia política de las sociedades occidentales que ofrece Dahl. A partir del análisis de la historia política de Estados Unidos y de la extensión de sus conclusiones al resto de las sociedades occidentales, Dahl plantea que la sociedad ha evolucionado de una situación en la que los recursos políticos estaban concentrados en pocas manos a otra en la que su posesión se ha dispersado en un espacio más amplio de la sociedad. Se parte de la necesidad de reconocer que los medios para influir en la política no se reducen únicamente al voto, sino que el poder económico, la posición social, los medios de opinión pública, etc. son recursos políticos desde el momento en que su posesión y uso determina la posibilidad de imprimir una determinada dirección a los asuntos políticos: En un sistema político donde casi todo adulto puede votar pero el conocimiento, la riqueza, la posición so-

${ }^{23}$ El darwinismo social de Pareto lo llevó a proponer que la vitalidad de una sociedad estaba determinada por la sana composición de sus élites, las cuales debían sobresalir en todas y cada una de las actividades sociales. Dahl nunca llega a proponer tal darwinismo, sin embargo, su teoría es mucho más reveladora y comprensible si se recurre a los autores de la teoría de las élites políticas: Vilfredo Pareto, Gaetano Mosca y Roberto Michels. 
POLIARQUÍA Y DEMOCRACIA

cial, el acceso a los funcionarios y otros recursos están distribuidos inequitativamente, ¿quién gobierna realmente? ${ }^{24}$

De este modo, resulta del mayor interés examinar el planteamiento que se realiza en torno a la evolución de la sociedad moderna: Dahl propone interpretar esta historia como la evolución desde una sociedad donde todos los recursos políticos -riqueza, prestigio, conocimientoestaban concentrados en un solo grupo social hasta llegar a una sociedad en donde cada uno de estos recursos se distribuye entre distintos grupos y el número de poseedores de recursos políticos se diversifica y multiplica. Refiriéndose específicamente a una ciudad de Estados Unidos, aunque como se dijo antes, sus conclusiones las extiende al resto de las sociedades occidentales, Dahl explica de esta manera ese proceso: "En el curso de los dos siglos anteriores, New Haven ha cambiado gradualmente de la oligarquía al pluralismo. Acompañando y probablemente causando este cambio -podría llamársele incluso revolución-sobresale una profunda alteración de la manera en la que los recursos políticos están distribuidos entre los ciudadanos de New Haven. Esta silenciosa revolución socioeconómica no sustituyó equidad por inequidad, sino que significó el cambio de desigualdades acumuladas en recursos políticos - para usar la expresión introducida hace un momento- a no acumulativas o inequidades dispersas." 25

En este sentido, aunque las sociedades modernas se guíen por el dogma de la igualdad intrínseca de los hombres, en cuestión de recursos políticos la posibilidad de la igualdad no puede plantearse seriamente, ni siquiera en términos de aspiración. Es necesario aceptar que para los requerimientos del sistema democrático basta que los recursos políticos estén en manos de distintos grupos, de distintas élites si se quiere, pero que no se encuentren reunidos y monopolizados en un solo grupo oligárquico. En estos términos, no es necesario llegar a la igualdad de la distribución de los recursos, sino a una desigualdad que proporcione diferentes tipos de recursos a unos y otros. Esto significa,

${ }^{24}$ Who governs?, p. 1.

${ }^{25}$ Ibid., p. 11. 
ROBERTO GARCÍA JURADO

en la raíz del planteamiento, que la disposición de los recursos políticos y económicos esté separada, y que dentro de ambas esferas haya no una sino varias élites.

Esta idea de la sociedad lo lleva a establecer que por lo que respecta a la estructura política existen fundamentalmente dos tipos de hombres: el homo civicus y el homo politicus. Esta separación destaca la idea de que el hombre necesita vivir en sociedad, pero no necesariamente involucrarse en la política. El homo civicus se caracteriza porque los recursos que tiene a su disposición los emplea en actividades distintas a la política; esto implica que así como invierte sus recursos fuera de la política, del mismo modo sus metas y recompensas estarán también fuera de las actividades políticas. Sucede lo contrario con el homo politicus, pues éste emplea sus recursos en las actividades políticas, es decir, ya sea para influir sobre las decisiones políticas o para invertirlos directamente en una carrera política, lo que significa que el cumplimiento de sus metas y la satisfacción de sus aspiraciones se encuentran precisamente dentro de la política. ${ }^{26}$

${ }^{26}$ Dahl realiza esta descripción fundamentalmente en Who governs?, pero la retoma en Modern political analisys, para abrir la clasificación a cuatro tipos de ciudadanos. 1) El estrato apolítico, constituido por la mayor parte de la sociedad y que no interviene en política debido a múltiples razones: porque espera mayores beneficios ocupándose de actividades distintas a la política; porque no percibe diferencias notables entre las opciones políticas que se le presentan; porque considera que su participación difícilmente cambiaría el resultado de los procesos políticos; porque piensa que el resultado que sea le será favorable; o porque piensa que el conocimiento que tiene es insuficiente; 2) El estrato político, que participa en la política porque considera los mismos factores que el estrato apolítico, pero haciendo una valoración totalmente contraria; 3) Los perseguidores de influencia -que es un subconjunto dentro del estrato político-cuentan con un alto nivel educativo, económico y social relativamente, y tienen como objetivo influir en las decisiones de gobierno; y 4) Los poderosos, que son un reducido grupo dentro de los perseguidores de influencia, quienes han tenido éxito en sus pretensiones y pueden considerarse poseedores de influencia y poder político. Cfr. Cap. 9. 
De esta manera, nuevamente con un afán meramente descriptivo que, a fin de cuentas, distorsiona aquello que describe, Dahl simplifica el problema del dominio político dentro de las sociedades humanas y propone que el hombre decide voluntariamente en qué esfera invierte sus recursos, suponiendo además que en términos relativos todos y cada uno tienen un cúmulo de recursos más o menos igual y que al invertirlos surten similares efectos.

Todas las sociedades humanas se dividen en gobernantes y gobernados, decía Mosca, pero a diferencia de él que consideraba a esta estructura como autoreproductiva y por lo tanto dotada de cierta rigidez e involuntariedad, Dahl considera que se elige libremente si se desea pertenecer a los dominadores o a los dominados, a los gobernantes o a los gobernados. No toma en cuenta que esta división política es el producto de algo más que las decisiones de los ciudadanos, pues si hemos de aceptar que en las sociedades modernas el acceso a la clase política está relativamente abierto, también habrá que señalar que su composición está determinada por algo más que una decisión personal.

Dahl, con su insistencia en el liderazgo político, económico y social, pretende resaltar un orden social eminentemente dinámico donde el liderazgo es simplemente una función de una persona determinada dentro de un área y momento determinados. Es decir, se puede ser líder o no, lo cual depende de múltiples factores, pero todos los ciudadanos tienen más o menos la misma posibilidad de llegar a ocupar esa posición dentro de alguna actividad social. Con ello, Dahl le quita a la sociedad toda rigidez institucional, elimina las líneas que separan a las clases sociales y las que diferencian la clase gobernante de la clase gobernada. Asimismo, de acuerdo con esto, los caminos de acceso a la élite política, económica y social están libres para los miembros de todos los sectores sociales, los obstáculos que impiden esta incorporación son mínimos, intrascendentes, todo depende de la elección personal de en qué cosa se desean invertir los recursos que la naturaleza le ha dado al hombre, reproduciendo así aquélla imagen lockeana del estado de naturaleza. Como en los mejores tiempos míticos de los 
Estados Unidos, las estructuras sociales son todo lo porosas que desee la voluntad individual.

Al examinar esta cuestión, Dahl cae en la misma indiferenciación y confusión que incurrió cuando trató indistintamente a la democracia como método decisorio y como régimen político. En el caso del control del liderazgo se repite esta confusión, pues concibe que se puede aplicar un control de poliarquía (es decir, de no-lideres sobre líderes) en cualquier organización social, ya sea ésta un sindicato, un partido político o un Estado.

Al despojar al gobierno de toda posibilidad de acción positiva, Dahl se ve constreñido a aceptar no sólo que la función de la política es vigilar a los gobernantes, sino que la virtud de la democracia radica en que es la mejor forma para controlarlos. No obstante, hay que señalar que en el mundo moderno esto no ha sido así, pues en las sociedades occidentales los gobiernos han sido en muchos casos activos promotores del desarrollo económico y social. De este modo, si en Estados Unidos, por ejemplo, el gobierno ha tenido una actuación digamos modesta en este aspecto, ello no debería ser factor para que Dahl considerara que así es en el resto del mundo occidental. ${ }^{27}$

62 Para finalizar esta cuestión, debe mencionarse que dados los sistemas representativos bajo los que debe funcionar la democracia moderna, sería necio ignorar que se requiere una fluida comunicación entre representados y representantes, así como un alto grado de control y vigilancia de los primeros sobre los segundos. Sin embargo, hacer recaer la democracia en este aspecto es también un exceso que no sólo desvirtúa el ideal democrático, sino que distorsiona la realidad.

${ }^{27}$ Guy Hermet expone las distintas funciones que ha asumido el Estado en el desarrollo de la burguesía de los países occidentales; en algunos ha desempeñado un papel marginal y en otros su actividad ha sido determinante. De hecho, se presenta una correlación negativa entre la intervención del Estado y el liberalismo; ahí donde ha sido menos relevante la participación estatal las ideologías liberales han arraigado con mayor fuerza, y a la inversa. Cfr. Las fronteras de la democracia, 1989, México, FCE. 
POLIARQUÍA Y DEMOCRACIA

\section{La poliarquía como pluralismo corporativo}

La confección misma del concepto de poliarquía no es del todo afortunada. El vocablo griego polis sugiere la idea de muchos, en tanto que arkós significa el gobierno o gobernante, es decir, atendiendo a sus raíces etimológicas, poliarquía significaría la existencia de muchos gobiernos o gobernantes en la sociedad. Este significado no sería congruente con el pensamiento de Dahl, pues de acuerdo a su propio planteamiento sólo puede haber un gobierno en la sociedad, el cual se diferencia de cualquier otra institución u organización social porque: El gobierno mantiene efectivamente el reclamo de la regulación exclusiva de la fuerza fisica para la observación de sus leyes en un territorio determinado. Aunque esta concepción del gobierno es difícil de aceptar sin más reflexión, permite mostrar cómo Dahl considera que existe uno y sólo un gobierno dentro de cada sociedad. ${ }^{28}$

En todo caso, hubiera sido mejor usar el concepto de policracia, en tanto que el vocablo griego kratós significa poder o fuerza, lo cual está mucho más cerca del contenido que Dahl le da a su concepto: la existencia de muchos polos de fuerza dentro de la sociedad. ${ }^{29}$

${ }^{28}$ El mismo Dahl no queda del todo satisfecho con esta definición y termina ofreciéndola a través de su planteamiento negativo: "Cuando un gran número de personas en un territorio determinado comienza a dudar o rechazar el reclamo del gobierno para regular la fuerza, entonces el propio Estado se encuentra en peligro de disolución." Cfr. Modern political analisys..., p. 11.

${ }^{29}$ El uso de estos conceptos no está libre de confusión: Carl Friedrich, por ejemplo, aplica el concepto de policracia al de una democracia de gabinete, es decir, a un organismo colegiado que toma decisiones mediante un proceso democrático. Cfr. La democracia como forma de vida y como forma política. En su Diccionario de política $\mathrm{R}$. Garzaro da las siguientes definiciones: "Poliarquía: Sistema político en que operan distintos centros de poder que llegan incluso a enfrentarse entre sí. Ésta era la situación política que existía en la Edad Media en Europa, a la que puso fin el absolutismo cuando concentró el monarca todo el poder en sus manos." y "Policracia: Régimen político en 
Éste es precisamente uno de los rasgos más importantes y una de las formas de entender la poliarquía: la existencia de muchas organizaciones dentro de la sociedad, las cuales deben tener un margen suficiente de autonomía relativa, es decir, contar con un campo de actividades en el que puedan tomar decisiones sin que sufran la injerencia o inhabilitación por parte de otra organización, aun cuando esa otra organización sea el Estado.

El principio de la libertad de asociación es uno de los dogmas constitucionales más importantes de la democracia moderna, con una significación y relevancia mucho mayor que en otro tipo de unidades politicas, dado que la diferencia entre el número de ciudadanos que componían una ciudad-Estado griega o una república italiana de principios de la era moderna contrasta con el número de ciudadanos con que cuentan los Estados modernos. Esta diferencia implica también una modificación en el funcionamiento y la vida política del Estado, pues no es lo mismo un Estado que cuente con diez mil ciudadanos, que otro que cuente con diez millones. Asimismo, tampoco es lo mismo ser un ciudadano de un Estado que cuenta con una asamblea pública encargada de tomar decisiones, que serlo de un Estado asentado en un extenso 64 territorio, donde existen varias ciudades y en el cual es inconcebible imaginar reunidos a todos los ciudadanos.

Estas diferencias hacen que el valor marginal de los ciudadanos de un Estado moderno sea menor al de formaciones políticas más pequeñas, como las que existieron en la Grecia clásica, por ejemplo. Asimismo, a pesar de contar con un sistema democrático a través del cual los

que el poder está distribuido. Desde que Locke y luego Montesquieu elaboraron la teoría de la división de poderes del Estado, la policracia prevalece en las estructuras politicas modernas, al menos teóricamente." En el mismo sentido, Herman Heller utiliza el concepto de poliarquía para describir la descentralización del poder político que existía en los Estados feudales. Cfr. Teoria del Estado. Como puede verse, dada la polisemia de estos conceptos, Dahl podría haber contribuido sensiblemente especificando la significación precisa que él atribuye a su poliarquía. 
ciudadanos se sienten partícipes de las decisiones políticas que hay que tomar, el ciudadano de un Estado moderno generalmente concibe al Estado como una entidad ajena y apartada de su actividad cotidiana, e imagina su poder como impersonal e inconmensurable, lo imagina pues como un Leviathan enorme y poderoso:

Entre las posibles fuentes de alienación en las democracias occidentales que pueden generar nuevas formas de oposición estructural está el mismo Leviathán democrático. Por Leviathán democrático quiero dar a entender el tipo de sistema político que se ha descrito en los capítulos de este libro, el producto de una larga evolución y una dura lucha, orientado al bienestar, centralizado, burocrático y controlado por la competencia entre poderosas élites organizadas y, en la perspectiva del ciudadano ordinario, un tanto remoto, distante, e impersonal aun en países como Noruega y Suecia. ${ }^{30}$

De este modo, considerando el tamaño de los Estados modernos y el menor peso marginal que tienen los ciudadanos dentro de ellos, las organizaciones sociales desempeñan una indispensable función de agrupación social e intermediación entre el ciudadano y el Estado. Mediante las organizaciones sociales se llena el enorme espacio que existe entre el ciudadano aislado, solitario y el distante, poderoso Estado. $^{31}$

${ }^{30}$ Robert Dahl, Political opposition in western societies, 1966, New Haven, University Yale Press, p. 399.

${ }^{31}$ En ¿Después de la revolución? (1994, España, Gedisa), Dahl examina de una forma muy interesante los distintos tipos de autoridad que existen en las organizaciones e instituciones de la sociedad moderna. Además, enuncia lo que él llama el "principio de las cajas chinas", consistente en descentralizar las decisiones sociales relevantes hasta el nivel donde los ciudadanos afectados por el resultado de ellas sean precisamente los facultados para tomarlas. 
En este sentido, es importante preservar y consagrar la libertad de asociación dentro de las sociedades modernas pues a través de ella el ciudadano puede recuperar su conciencia de contribución y relevancia política. Además, las organizaciones sociales son frenos y contrapesos reales del poder del Estado, pues ante una determinada acción gubernamental, es mucho más significativo y efectivo oponer la resistencia de una organización que la resistencia de un grupo de ciudadanos aislados, los cuales, por su mismo aislamiento, muy probablemente ni siquiera sean capaces de oponer resistencia.

De este modo, las organizaciones tienen la virtud de operar como centros de integración social, generadores de ideas y propuestas, creadores y difusores de información y, sobre todo, como instancias de control sobre otras organizaciones y sobre el propio gobierno. Como puede observarse, el pluralismo que resulta de esta libertad de asociación constituye un tejido social que permite a los ciudadanos defenderse de la acción de otras organizaciones, pero sobre todo de la acción del Estado. Además, ésta es una consecuencia de la visión de la sociedad que tiene Dahl, una sociedad basada en el conflicto de intereses más que en la comunidad de aspiraciones. De ahí también que en su esquema resulte tan importante la existencia de múltiples organizaciones sociales, las cuales puedan traslaparse de todas las maneras posibles, puesto que así es más dificil enfrentar una situación de polarización en la lucha de clases sociales, y los conflictos que se generen serán sobre todo controversias entre distintas organizaciones, las cuales disputarán sobre asuntos particulares, y para cada uno de ellos contarán con un determinado grupo de organizaciones aliadas y enemigas, cuya conformación cambiará al tratarse otro asunto particular, evitando de esa forma que la sociedad se divida por una sola línea de conflicto que haga peligrar el orden social.

Así, el pluralismo es primordialmente una forma de dispersar los recursos y los poderes dentro de la sociedad, pero no sólo separando las organizaciones privadas de las públicas, sino también dentro de cada una de estas esferas. Es decir, Dahl concibe que existen tres tipos fundamentales de organizaciones: 1) Gubernamentales (poder ejecutivo, 
burocracia, poder legislativo, y poder judicial), 2) Políticas (partidos, grupos de interés), y 3 ) Económicas (empresas y sindicatos). ${ }^{32}$

De este modo, el pluralismo es tan importante que se puede imaginar una estructura pluralista aun en una sociedad no democrática, pero es imposible imaginar una democracia sin pluralismo.

En nombre de este pluralismo, Dahl llega a justificar la existencia de prácticas oligárquicas en los partidos políticos. Para Dahl lo más importante del sistema de partidos es que sea capaz de ofrecer distintas ofertas políticas y electorales a los ciudadanos. En este sentido, de la misma forma que lo hiciera Michels, reconoce que los partidos políticos están controlados por una élite que reproduce una estructura oligárquica. Es decir, que los partidos políticos no albergan en su conformación un sistema democrático, aunque en el Estado provoquen un efecto democrático.

Es necesario señalar que la idea de pluralismo de Dahl es bastante limitada, pues se refiere sobre todo a un pluralismo corporativo, como él mismo lo plantea: "En las expresiones pluralismo democrático o democracia pluralista, los términos pluralismo y pluralista se refieren al pluralismo organizativo, esto es, a la existencia de una pluralidad de organizaciones (subsistemas) relativamente autónomas (independientes) en el ámbito de un Estado." 33

Esta concepción es bastante limitada, ya que en la sociedad moderna el pluralismo que se requiere debe ser al menos de tres tipos: político, social y cultural.

Dahl contrapone evidentemente al pluralismo un modelo de sociedad monolítico y totalitario, con lo cual, por contraste, el pluralismo adquiere un valor mayor. Sin embargo, el pluralismo que concibe Dahl puede degenerar hasta el grado de ofrecer la idea de que el rumbo

${ }^{32}$ Esta clasificación está tomada de Los dilemas del pluralismo..., aunque en Politics, economics and welfare señala que en la sociedad moderna las organizaciones más importantes de la sociedad moderna son cuatro: el gobierno, los partidos, las empresas y los sindicatos.

${ }^{33}$ Los dilemas del pluralismo..., op. cit., p. 16. 
ROBERTO GARCÍA JURADO

social es el producto de una interacción de organizaciones y, por consiguiente, no es responsabilidad de ninguna de ellas. Esta formulación vuelve a destacar la valoración negativa que el liberalismo asigna a la acción estatal: se asume que la conducción social guiada por el Estado es necesariamente negativa, y por lo tanto es mejor que no recaiga en él.

Sin embargo, hay que advertir que en el mundo moderno existen organizaciones muy poderosas, que con mayores recursos económicos y humanos que los de un gobierno llegan a influir y determinar el rumbo de la acción gubernamental, lo cual es incompatible con los ideales democráticos. ${ }^{34}$

Esta argumentación parecería favorecer la idea de Dahl en el sentido de que es conveniente que exista una pluralidad de organizaciones que interactúen, controlándose y limitándose mutuamente. Sin embargo, hay que señalar que no parece legítimo que el rumbo y sentido de la acción gubernamental sea determinado por una o por varias corporaciones; ni el monopolio ni el oligopolio son opciones adecuadas para elegir el modelo de acción social sobre el Estado.

Al examinar las ideas que sobre la democracia y la poliarquía tiene Dahl, es inevitable pensar y remontarse a la realidad de los Estados Unidos. Y éste es uno de los defectos más grandes que caracterizan a

${ }^{34}$ Los riesgos de este rasgo del pluralismo son considerables, Dahl enumera algunos de ellos: 1) Ayudar a mantener injusticias: los individuos que pertenecen a organizaciones determinadas pueden disfrutar de una mayor influencia política o económica de la que tienen los que están fuera de ellas, 2) Deformar la conciencia cívica: la defensa de los intereses de una organización puede conducir a situar éstos por encima de los intereses de la sociedad en su conjunto; y 3 ) Distorsionar de la agenda pública: la presión de determinadas organizaciones puede modificar el programa de la agenda pública hacia fines específicos. Ibid. Cap. III. Roger Benjamin no considera que sean sólo riesgos, sino una característica de este sistema: "Lejos de asegurar la democracia, el pluralismo congela los privilegios de los intereses existentes que apoyan una sociedad altamente estratificada; una sociedad en la cual los pobres, los desorganizados salen perdiendo." Los límites de la política, 1992, México, Alianza, p. 98. 


\section{POLIARQUIAA Y DEMOCRACIA}

las tesis de Dahl, pues en lugar de proponer un modelo social construido a partir de lo que significa la teoría democrática para el pensamiento moderno, lo que ha hecho es examinar las características y rasgos del sistema político norteamericano; después, a este conjunto le ha llamado democracia y, considerando sus defectos, poliarquía, pasando a compararlo con sistemas de otros países para ver qué tanto se aproximan o se alejan de este modelo-realidad.

No puede decirse que los rasgos que identifica Dahl como democráticos en los Estados Unidos estén totalmente ausentes en los otros países occidentales, de hecho, muchos de ellos pueden observarse en sistemas considerados democráticos, sin embargo, no podría aceptarse sin reflexión alguna que ése sea el modelo a seguir. Puede aceptarse que la descripción de la democracia que hace Dahl es correcta en una gran parte, pero eso no justifica que se deba tomar como un modelo prescriptivo, a partir del cual se comparen el resto de las sociedades y vean si se acercan o no a la democracia usando ese paradigma.

Para mostrar cómo Dahl intenta justificar el sistema político de su país a toda costa, basta citar aquí la interpretación que hace de la exclusión de los derechos políticos que sufrieron los negros hasta finales del siglo pasado, para no hablar del racismo y xenofobia que persisten en ese país. En Democracy in the United States dice: "Como veremos, durante casi toda su historia los Estados Unidos han tenido un sistema político dual: una poliarquía entre blancos y una hegemonía para los negros sureños." 35

Muy probablemente éste sea uno de los pasajes más desafortunados de los escritos de Robert Dahl, no obstante, aunque su teoría política y su concepto de poliarquía adolezcan de las deficiencias e incongruencias que aquí se han señalado, su aportación al campo de la ciencia política ha sido muy sugerente, razón por la cual debe ser considerado uno de los principales interlocutores en la polémica de la teoría política contemporánea. 